\title{
Bifidobacteria in Broiler Starter Rations: Factors Affecting Survival*
}

\author{
S.M. Rose, H.W. Modler and R.C. McKellar \\ Centre for Food and Animal Research, Research Branch, Agriculture Canada, Ottawa, Canada, K1A 0C6
}

(Received for publication, February 24, 1994)

\begin{abstract}
The viability of freeze-dried cells of bifidobacteria ( $B$. thermophilum ATCC 25525) in broiler starter rations was monitored at different storage temperatures during a twelve-week period. A total of five treatments (control plus four bifidogenic factors), at low $(1.55 \%$ moisture, $\left.\mathrm{a}_{\mathrm{w}}<0.4\right)$ and high water activity $\left(10.52 \%\right.$ moisture, $\left.\mathrm{a}_{\mathrm{w}}=0.64\right)$ were included in the study. Results indicated that lower moisture and water activity enhances the survival of bifidobacteria when incorporated into feeds. Refrigeration temperatures $\left(5^{\circ} \mathrm{C}\right.$ and $\left.-18^{\circ} \mathrm{C}\right)$ also increase the survival of bifidobacteria in rations stored for up to twelve weeks. Bifidogenic factors, when included in the feeds, had a limited protective effect on bacterial survival. The use of probiotics, containing bifidobacteria, is an area that needs to be closely evaluated before they can be added to animal rations under commercial conditions.
\end{abstract}

Key words: bifidobacteria; water activity; survival; feeds; probiotics

Advances and new developments in animal husbandry have become an area of interest over the past few years in response to the growing concerns in the poultry industry with regard to increased incidences of salmonella and other potential pathogens (19). In the past, the use of antibiotics has been the most common method of suppressing undesirable microorganisms; however, the extensive use of antibiotics in animal feeds may have contributed to the high antibiotic resistance of salmonella species that is causing much concern (13). Emphasis has now been placed on the use of probiotics as an alternative to antibiotics $(2,5)$.

Probiotics is not a new concept and has been used since the 1900's but the documented evidence of its value is still inconclusive $(2,4,16,19)$. The word probiotic was revised by Fuller (2) to read "a live microbial feed supplement which beneficially affects the host animal by impoving its intestinal microbial balance." The importance of this statement and others is that emphasis must be placed on the words 'live cells.' However the definition of probiotics has since expanded to cover treatments that exert beneficial effects in the mouth, gastrointestinal tract, in the

* Contribution No. 2214 from the Centre for Food and Animal Research 
upper respiratory tract or in the urogenital tract (3). Probiotics can be administered to the animal by various methods such as a paste or suspension, or by addition to the drinking water. Supplementation via the diet (feed) is considered to be more convenient and ensures a consistent supply (22). Incorporation in a feed, however, poses several problems with respect to the maintenance of a viable probiotic microorganism. As stated by Pollmann, (15) "the theoretical concept of probiotics has some intriguing scientific merit, but very few commercial products presently enjoy much market potential."

Variability in the results as reported in the literature could be dependent on the viability and stability of the microbial culture. The latter are influenced by storage conditions such as temperature, humidity and $\mathrm{pH}$; production techniques such as pelleting and spraying; or the presence of cryoprotective agents and antibiotics in the feeds. Also important are the doses applied and the frequency of application $(15,16,21)$.

The results of a study by Pollmann and Bandyk (16), demonstrated that the stability of viable lactobacilli can be influenced by the storage environment (heat and humidity), length of storage and by the type of medication in the feed. The use of lincomycin in the feed had a slightly adverse effect on product stability. They found that feed samples containing lactobacilli had prolonged stability when stored at refrigerated temperatures $\left(4^{\circ} \mathrm{C}\right)$ as compared to other environments. The largest reduction in viability occurred during the first week of storage.

In a review paper by Vanbelle et al. (21) a requirement for an ideal probiotic is that the bacteria must be in a viable state (easy proliferation "in vivo" and "in vitro") and it seems that $10^{6}-10^{7} \mathrm{CFU} / \mathrm{g}$ feed are necessary. The shelf life of viable microorganisms in mixed feeds is an area of uncertainty and further studies are needed to evaluate the viability of these microorganisms when added to feeds and stored over time. Fuller (2) suggested that poor quality control is a problem with some commercial preparations.

The purpose of this study was to determine the effects of storage temperatures $\left(37,22,5\right.$, and $\left.-18^{\circ} \mathrm{C}\right)$, time, moisture content/water activity of rations and bifidogenic factors (JAF, inulin, Sal Curb) on bifidobacteria added to the rations as freeze-dried cells (FDB). Bifidogenic factors are compounds that provide a source of energy to the bifidobacteria and survive direct metabolism by the host in the large bowel or cecum. These factors have been reviewed in detail by Modler et al $(8,11)$.

\section{MATERIALS AND METHODS}

Preparation of freeze-dried cells of bifidobacteria $(F D B)$. Bifidobacterium thermophilum (ATCC 25525) were grown in trypticase-phytone-yeast extract (TPY) medium (18) for $24 \mathrm{hr}$ in an anaerobic environment and incubated at a temperature of $37^{\circ} \mathrm{C}$. A small incubator was exhausted and flooded with $100 \%$ carbon dioxide three times to obtain anaerobic conditions. The cells were washed with $0.05 \mathrm{~m}$ phosphate buffer at $\mathrm{pH} 7.5$ and then concentrated by centrifugation (Cryofuge 8,500) at a temperature of $2^{\circ} \mathrm{C}$ and at a relative centrifugal force of $8,000 \times g$. The cells were 
resuspended in a minimal amount of phosphate buffer and mixed with an equal volume of sterilized skim milk (reconstituted to $11 \%$ solids). The cell mixture was frozen to $-30^{\circ} \mathrm{C}$ overnight and then freeze dried for three to four days at a plate temperature of $30^{\circ} \mathrm{C}$. The freeze-dried cells were stored in a sterilized container for immediate inclusion in the broiler starter rations or frozen at $-80^{\circ} \mathrm{C}$. Viability of $B$. thermophilum in the freeze-dried powder (FDB) was determined by enumerating on BL agar (Blood-liver glucose agar) $(6,8-10,17,20)$.

Diet preparation. Five batches of poultry starter rations (referred to as nonfreezedried feed, NFD) were prepared at the Greenbelt farm of Agriculture Canada, in preparation for a study to examine the ability of bifidogenic factors and organic acids to inhibit the growth of salmonella in broilers challenged with $S$. typhimurium (7). The rations consisted of a control group (C) and four other diets with the following bifidogenic factors: 5\% Jerusalem Artichoke Flour (JAF) ; 2.5\% inulin (IN); $1 \%$ Sal Curb (SC); and 5\% JAF plus $1 \% \mathrm{SC}(\mathrm{JAF} / \mathrm{SC})$. The inulin was a commercial preparation (trade name Raftiline) supplied by the Tienen Sugar Co. (Tienen, Belgium). Agri-Marketing Corp. (Mont-Saint-Hilaire, Quebec) supplied the organic acid preparation known as Sal Curb. A four or five kilogram sample of each diet was collected from the Greenbelt farm mill prior to the addition of the liquid tallow ( $2 \%$ of the diet) which is a normal constituent of poultry rations. The samples were transported to the Centre for Food and Animal Research so that bifidobacteria could be added. The major ingredients in the rations consisted of wheat, soybean meal, corn, fishmeal and lactose-free whey. The bacterial cells were not mixed with the fat as initially intended because a good blend could not be obtained. The fat was sterilized, cooled to $35^{\circ} \mathrm{C}$ and added at a rate of $2 \%$ to the diets prior to the addition of freeze-dried bifidobacteria cells (FDB) which were also added at a rate of $2 \%$. The goal was to obtain $10^{6}-10^{7}$ CFU of bifidobacteria per gram of feed. The prepared feed mixture was placed in a Twin Shelf Dry Blender (The Patterson Kelley Co., East Stroudsburg, Pennsylvania), and rotated 30 minutes for each diet preparation. A one-hundred-gram sample of each diet was placed in separate labelled bags for subsequent storage at four different temperatures $(37,22,5$, and $\left.-18^{\circ} \mathrm{C}\right)$. Samples of freeze-dried B. thermophilum were also stored in 6-ml plastic bags at these same temperatures. All samples were prepared in duplicate.

This procedure was repeated a second time except that the poultry rations were freeze dried (prior to the addition of the fat and bacteria) to determine the effect of moisture and water activity on viability of the bifidobacteria. These rations are the freeze-dried feeds (FD). Moisture contents of the feed preparations were determined by the method of Clark et al. (1) which is a modification to the AOAC method. Water activity $\left(a_{w}\right)$ was determined using a Lufft meter (Model No. 5803, Germany).

Testing of feeds for the viability of bifidobacteria. Initial plate counts were determined for the freeze-dried bifidobacterial cells and for the five different diets $(\mathrm{C}, \mathrm{JAF}$, IN, SC, JAF \& SC). This was taken as the day zero count. In addition, total plate counts were conducted on the feeds to check for initial loads of bacteria. The viability of the bifidobacteria were determined by enumerating cultures on BL 
agar at two-week intervals, up to and including the 12th week. The sample size was $10 \mathrm{~g}$ each for the feeds and $1 \mathrm{~g}$ for the freeze-dried bacteria. The sample was allowed to hydrate for $15 \mathrm{~min}$ in peptone water before serial dilutions were made. Sampling was done in duplicate with two sets of replicates being plated on BL agar and incubated in a carbon dioxide environment for $48-72 \mathrm{hr}$ as previously described. $B$. thermophilum colonies were easily recognised by their characteristic growth on the media and were further examined microscopically. The colonies were also compared with those from the freeze dried sample of $B$. thermophilum that was stored and tested along with the feed samples at the same temperature and time.

Statistical analysis. Multifactor analysis of variance (ANOVA) and multiple regression analysis (MRA) were performed using the STATGRAPHICS ${ }^{\circledR}$ Plus software (Manugistics, Rockport, MD, U.S.A.). ANOVA was used to compare the means of 5 diets $\times 4$ temperatures $\times 4$ storage times (freeze-dried feed) and 5 diets $\times 2$ temperatures $\times 4$ storage times (nonfreeze-dried feeds). Main effects (diet, temperature and time), interactions and quadratic effects were examined. Significant differences $(p \leq 0.05)$ among the means were determined using the least significant difference method. MRA was used to determine regression coefficients for both freeze-dried and nonfreeze-dried feeds. Main effects were time and temperature (diet effects were ignored), and interactions and quadratic effects were also considered.

\section{RESULTS AND DISCUSSION}

Preliminary examination of the data revealed considerable differences between freeze-dried (FD) feed with $1.55 \%$ moisture $\left(a_{w}<0.4\right)$ and nonfreeze-dried feed (NFD) with $10.52 \%$ moisture $\left(a_{w}=0.64\right)$. Survival in NFD feed was generally poorer; storage at $22^{\circ}$ and $37^{\circ} \mathrm{C}$ resulted in no survival after the minimum storage time (2 weeks).

Table 1. Comparison of survival of freeze-dried Bifidobacterium thermophilum (FDB) alone or in various freeze-dried or nonfreeze-dried diets

\begin{tabular}{lcc}
\hline Treatment* & Freeze-dried feed & Nonfreeze-dried feed \\
\hline & $\ldots .86^{b}$ & $\ldots .77^{b}$ \\
FDB & $7.09 a$ & $5.61^{a}$ \\
Control & $7.17 a$ & $5.83^{a}$ \\
SC & $7.09 a$ & $5.73^{a}$ \\
JAF & $7.12^{a}$ & $5.70^{a}$ \\
SC+JAF & $7.08^{a}$ & $5.82^{a}$ \\
IN & & \\
\hline
\end{tabular}

* FDB, freeze-dried bacteria before addition to the rations for each set of freeze-dried or nonfreeze-dried diets; SC, Sal-Curb; JAF, Jerusalem artichoke flour; IN, inulin.

$a, b$ Values in the same column not followed by the same letter are significantly $(p \leq 0.05)$ different. Multifactor ANOVA was performed with 6 diets (FDB considered as a diet) $\times 2$ temperatures $\times 4$ times. 
Table 2. Multifactor analysis of variance of survival of Bifidobacterium thermophilum in freeze-dried feed by diet, temperature, and time

\begin{tabular}{lccccc}
\hline \multicolumn{1}{c}{ Source } & S.S. & D.F. & M.S. & F & $p$ \\
\hline Main effects & & & & & \\
$\quad$ Diet & 0.0616 & 4 & 0.0154 & 2.535 & 0.0465 \\
Temperature & 98.48 & 3 & 32.83 & $5,403.0$ & 0.0000 \\
$\quad$ Time & 7.994 & 3 & 2.665 & 438.6 & 0.0000 \\
Interactions & & & & & \\
$\quad$ Diet $\times$ Temperature & 0.9238 & 12 & 0.0770 & 12.67 & 0.0000 \\
Diet $\times$ Time & 0.4535 & 12 & 0.0378 & 6.220 & 0.0000 \\
Temperature $\times$ Time & 10.36 & 9 & 1.151 & 189.5 & 0.0000 \\
Diet $\times$ Temperature $\times$ Time & 1.781 & 36 & 0.0495 & 8.143 & 0.0000 \\
Residual & 0.4860 & 80 & 0.0061 & & \\
Total (corrected) & 120.5 & 159 & & & \\
\hline
\end{tabular}

S.S., sum of squares; D.F., degrees of freedom; M.S., mean squares; F, F-ratio; $p$; level of significance.

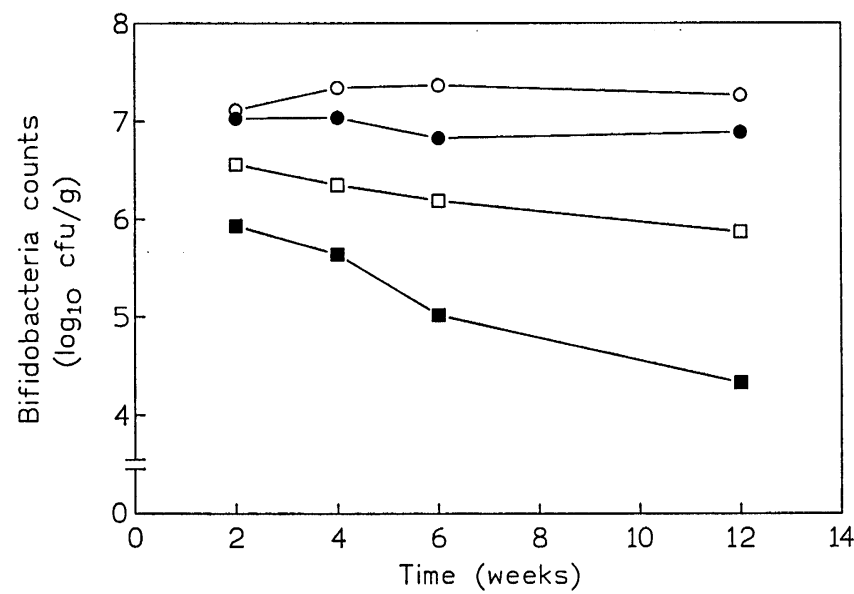

Fig. 1. Survival of Bifidobacterium thermophilum in freeze-dried feed stored at $-18^{\circ} \mathrm{C}(\mathrm{O})$, $5^{\circ} \mathrm{C}(\bullet), 22^{\circ} \mathrm{C}(\square)$, and $37^{\circ} \mathrm{C}(\boldsymbol{\square})$.

Table 1 shows the effect of feed and diet on survival averaged over all times at $-18^{\circ}$ and $5^{\circ} \mathrm{C}$. There was generally no significant effect of diet in FD or NFD feed for this averaged value; however, survival in all diets was significantly $(p \leq 0.05)$ poorer than survival of freeze-dried bacteria (FDB) stored in the absence of any diet.

Multi-Factor ANOVA of FD feeds revealed that all main effects, second- and third-order interactions were significant $(p \leq 0.05)$; however, temperature, time, and their interaction were the most important factors (Table 2). Figure 1 shows the time/temperature interactions for FD feeds. Survival was good at temperatures $\leq 5^{\circ} \mathrm{C}$; counts did not change markedly over the 12 -week period. In contrast, significant decreases in counts were observed at $22^{\circ}$ and $37^{\circ} \mathrm{C}$ within 4 weeks. 
Table 3. Multifactor analysis of variance of survival of Bifidobacterium thermophilum in nonfreeze-dried feed by diet, temperature, and time

\begin{tabular}{llllcc}
\hline \multicolumn{1}{c}{ Source } & S.S. & D.F. & M.S. & F & $p$ \\
\hline Main effects & & & & & \\
Diet & 0.5216 & 4 & 0.1304 & 28.332 & 0.0000 \\
Temperature & 8.842 & 1 & 8.842 & $1,921.0$ & 0.0000 \\
$\quad$ Time & 17.01 & 3 & 5.669 & $1,231.6$ & 0.0000 \\
Interactions & & & & & \\
$\quad$ Diet $\times$ Temperature & 2.1537 & 4 & 0.5384 & 116.9 & 0.0000 \\
Diet $\times$ Time & 0.4862 & 12 & 0.0405 & 8.804 & 0.0000 \\
Temperature $\times$ Time & 3.988 & 12 & 1.329 & 288.8 & 0.0000 \\
Diet $\times$ Temperature $\times$ Time & 0.472 & 12 & 0.0393 & 8.539 & 0.0000 \\
Residual & 0.1840 & 40 & 0.0046 & & \\
Total (corrected) & 33.65 & 79 & & & \\
\hline S.S., sum of squares; D.F., degrees of freedom; M.S., mean squares; F, F-ratio; $p$, level of \\
significance.
\end{tabular}

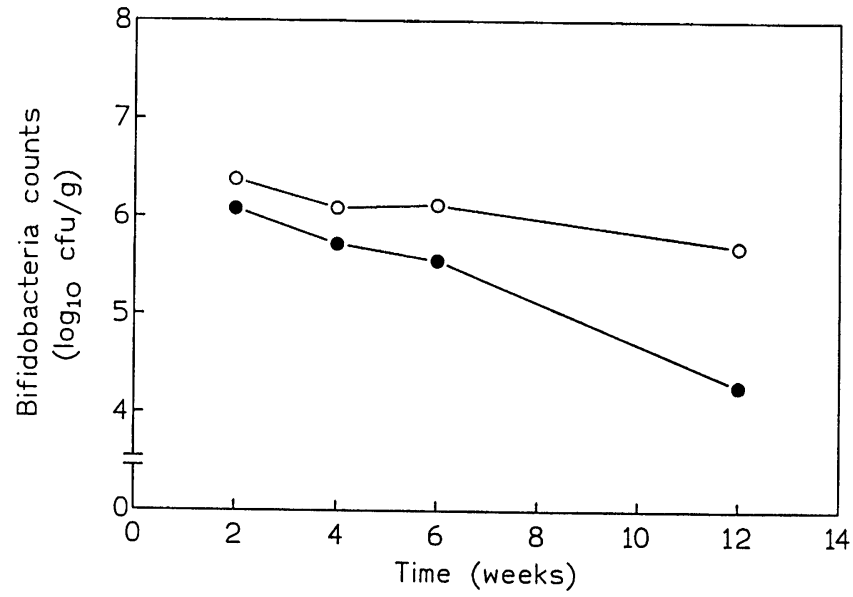

Fig. 2. Survival of $B$. thermophilum in nonfreeze-dried feed stored at $-18^{\circ} \mathrm{C}(\mathrm{O})$ and $5^{\circ} \mathrm{C}(\bullet)$.

A similar analysis of NFD feeds revealed that all main effects and interactions were significant. Time and temperature were highly significant factors, as was the interaction between these two factors. The interaction between diet and temperature was more significant than the effect of diet alone (Table 3).

The interaction between time and temperature for NFD feeds is shown in Fig. 2. As mentioned earlier, there was no survival after 2 weeks at either $22^{\circ}$ or $37^{\circ} \mathrm{C}$. At both $-18^{\circ}$ and $5^{\circ} \mathrm{C}$, significant losses of cells were noted after 4 weeks, with the most dramatic decrease occurring at $5^{\circ} \mathrm{C}$ between 6 and 12 weeks.

Interaction between diet and temperature for NFD feeds is shown in Table 4 . At $-18^{\circ} \mathrm{C}$, JAF and IN provided the best protection overall, with counts for inulin 
Table 4. Effect of temperature on survival of Bifidobacterium thermophilum in nonfreeze-dried feed

\begin{tabular}{llc}
\hline \multirow{2}{*}{ Feed } & \multicolumn{2}{c}{ Temperature $\left({ }^{\circ} \mathrm{C}\right)$} \\
\cline { 2 - 3 } & \multicolumn{1}{c}{-18} & 5 \\
\hline Control & $\ldots .98 a, b$ & $5.24 a$ \\
JAF & $6.24^{b, c}$ & $5.22^{a}$ \\
IN & $6.34^{c}$ & $5.32^{a}$ \\
SC & $5.95^{a, b}$ & $5.71^{a}$ \\
SC+JAF & $5.85^{a}$ & $5.54^{a}$ \\
\hline$a, b, c$ Values in the same column not followed by the same letter are significantly $(p \leq 0.05)$
\end{tabular}

Table 5. Multiple regression coefficients for predicting survival of Bifidobacterium thermophilum in freeze-dried and nonfreeze-dried feeds

\begin{tabular}{lcc}
\hline \multicolumn{1}{c}{ Factor } & Freeze-dried & Nonfreeze-dried \\
\hline Constant & 7.239 & 6.481 \\
Temperature & -0.0054 & - \\
Time & -0.0244 & -0.155 \\
(Temperature) $^{2}$ & -0.0007 & - \\
Time $\times$ Temperature & -0.003 & -0.0051 \\
$\mathbf{r}^{2}$ & 0.948 & 0.869 \\
\hline
\end{tabular}

significantly $(p \leq 0.05)$ greater than the control. At $5^{\circ} \mathrm{C}$, these two treatments were poorer than all other treatments with the exception of the control feed, although differences were not significant $(p>0.05)$.

MRA was used to determine the extent to which the two quantitative factors, time and temperature, could be used to predict survival of $B$. thermophilum, assuming no diet effect. A comparison of regression coefficients is given in Table 5. An excellent correlation $\left(\mathrm{r}^{2}=0.948\right)$ was obtained with FD feeds, while the value for NFD feeds was slightly lower. Temperature was a more important factor for accounting for survival differences between FD and NFD rations. Quadratic effects of temperature influenced survival in FD feeds, while the interaction between time and temperature was important for both FD and NFD feeds.

The relationship between predicted and experimental values for survival of B. thermophilum is shown in Fig. 3 (FD feeds) and Fig. 4 (NFD feeds). The variations in the experimental data points at each predicted value are due to the diet effect noted above. The variation is particularly noticeable at lower survival with FD feeds.

These results indicate that moisture, and thus water activity, significantly impacts on the survival of bifidobacteria. The initial count of viable cells in the freeze-dried bifidobacteria (FDB) was $9.00 \log _{10} \mathrm{CFU} / \mathrm{g}$ but only $6.64 \log _{10} \mathrm{CFU} / \mathrm{g}$ were recovered from the NFD feeds at $10.52 \%$ moisture, $a_{w}=0.64$ while all the bacteria $\left(7.30 \log _{10} \mathrm{CFU} / \mathrm{g}\right)$ were recovered in the FD feeds $\left(1.55 \%\right.$ moisture, $\mathrm{a}_{\mathrm{w}}<$ 


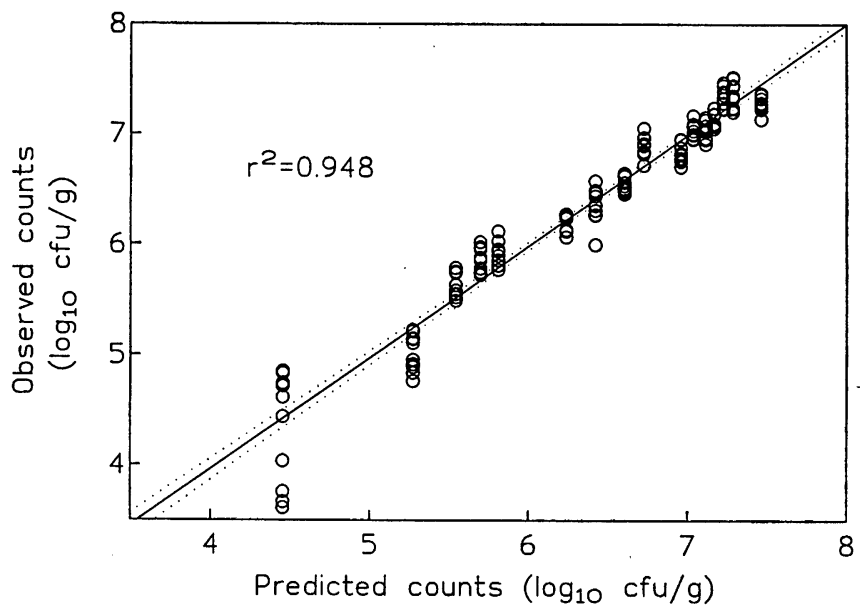

Fig. 3. Comparison of predicted and experimental survival of $B$. thermophilum in freezedried feed.

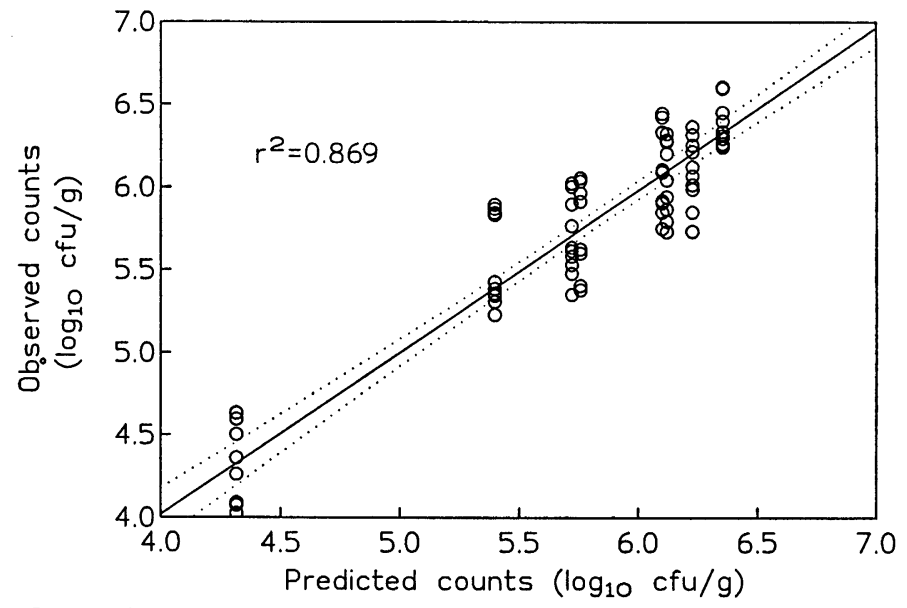

Fig. 4. Comparison of predicted and experimental survival of $B$. thermophilum in nonfreeze-dried feed.

0.4 ) when the $2 \%$ FDB was added to the rations. Again the higher value in the freeze-dried feed and in the FDB is attributed to the lower moisture content and water activity. In a study by Nagawa et al. (12), it was determined that the optimum residual water content in freeze-dried powder for bifidobacterium stability was about $3.5 \%$ or less. It was also determined that the packaging material is of importance with regard to water vapor permeability. Packaging material containing aluminium was considered to be the better choice as a barrier to water vapor.

The data have clearly shown that $B$. thermophilum survives best in freeze-dried 
feeds, and there is less mortality with lower temperatures and shorter storage times. The effect of diet was less important than the influence of temperature and time. It should be pointed out, however, that due to the lack of replication of rations, accuracy of assessment of diet effects may have been compromised.

Most testing is needed with regards to the viability of bifidobacteria when added in animal feed rations. In addition to evaluating the mechanisms of introducing probiotic bacteria, further testing is needed to determine the effect of feed ingredients (bifidogenic factors), moisture content/water activity, temperatures, and packaging materials. We are still at an early stage in the development of consistently effective probiotics. It is important that we ensure that the cultures used maintain their desirable characteristics during product manufacture (14).

Acknowledgements. The authors wish to thank G. Butler for assistance with the statistical analysis.

\section{REFERENCES}

(1) Clark, J.L., D.M. Barbano, and C.E. Dunham. 1989. Comparison of two methods for determination of total solids content of milk: collaborative study. J. Assoc. Off. Anal. Chem. 72: 712718.

(2) Fuller, R. 1989. Probiotics in man and animals. J. Appl. Bacteriol. 66: 365-378.

(3) Havenaar, R., B. Ten Brink, and J.H.J. Huis In't Veld. 1992. p. 209-224. In R. Fuller (ed.), Probiotics: the scientific basic, Chapman \& Hall, New York.

(4) Hoover, D.G., and D.B. Hughes. 1991. Current status and future trends of bifidobacteriarelated research and products in the U.S.A. Bifidobacteria Microflora 10: 113-121.

(5) Jernigan, M.A., A.S. Arafa, and R.D. Miles. 1985. Probiotics in poultry nutrition-a review. World's Poult. Sci. J. 41: 99-107.

(6) Laroia, S., and J.H. Martin. 1991. Methods of enumerating and propagating bifidobacteria. Cult. Prod. J. 26: 32-33.

(7) Modler, H.W. 1992. Compounds which enhance the growth of probiotic bacteria. p. 35-44. In Proc. Int. roundtable on animal feed biotechnology, Ottawa, Feb. 4-6, 1992.

(8) Modler, H.W., R.C. McKellar, and M. Yaguchi. 1990. Bifidobacteria \& bifidogenic factors. Can. Int. Food Sci. Technol. J. 23: 29-41.

(9) Modler, H.W., and L. Villa-Garcia. 1993. The growth of Bifidobacterium longum in a whey-based medium and viability of this organism in frozen yogurt with low \& high levels of developed acidity. Cul. Prod. J. 23: 4-8.

(10) Modler, H.W., J.L. Spencer, and S. Rose. 1993. Developments in the application of probiotics containing bifidobacteria. Lactic acid bacteria research in Canada workshop U of A, Edmonton, Alberta. June 23-25, 1993.

(11) Modler, H.W. 1994. Bifidogenic factors-sources, metabolism and application. Int. Dairy J. 4: $383-407$.

(12) Nagawa, M., A. Nakabayashi, and S. Fujino. 1988. Preparation of the bifidus milk powder. J. Dairy Sci. 71 : 1777-1782.

(13) Neu, H.C. 1992. The crisis in antibiotic resistance. Science 257: 1064-1073.

(14) O'Sullivan, M.G., G. Thornton, G.C. O'Sullivan, and J.K. Collins. 1992. Probiotic bacteria: mith or reality?. Trends Food Sci. Technol. 3: 309-314.

(15) Pollmann, D.S. 1992. Probiotics in swine diets. p. 65-69. In Proc. Int. roundtable on animal feed biotechnology, Ottawa, Ont. Feb. 4-6, 1992.

(16) Pollmann, D.S., and C.A. Bandyk. 1984. Stability of viable lactobacillus products. Anim. Feed Sci. Technol. 11: 261-267.

(17) Răsic, J. Lj., and J.A. Kurmann. 1983. Bifidobacteria and their role, Birkhäuser Verlog, Boston. 
(18) Scardovi, V. 1986. Genus Bifidobacterium, p. 1418-1434. In C.H. Sneath, N.S. Mair, M.E. Sharpe, and J.G. Holt (eds.), Bergey's manual of systematic bacteriology, 9th ed., vol. 2, Williams and Wilkins publishers, Baltimore.

(19) Schleifer, J.H. 1985. A review of the efficacy and mechanism of competitive exclusion for the control of salmonella in poultry. World's Poult. Sci. J. 41 : 72-83.

(20) Teraguchi, S., M. Uehara, K. Ogawa, and T. Mitsuoka. 1978. Enumeration of bifidobacteria in dairy products. Jpn. J. Bacteriol. 33: 753-761 (Translated from Japanese).

(21) Vanbelle, M., E. Teller, and M. Focant. 1990. Probiotics in animal nutrition: a review. Arch. Anim. Nutr. 40: 543-567.

(22) Williams, P.E.V. 1992. A feed compounders perspective of probiotics. p. 51-63. In Proc. Arkansas nutrition conference, Fayetteville, Arkansas, Sept. 15-17, 1992. 